www.jmscr.igmpublication.org

Impact Factor (SJIF): 6.379

Index Copernicus Value: 71.58

ISSN (e)-2347-176x ISSN (p) 2455-0450

crossref DOI: _https://dx.doi.org/10.18535/jmscr/v6i5.66

Journal Of Medical Science And Clinical Research

\title{
A Comparative Study in Assessing the Improvement of Dysphagia in between Ischemic and Hemorrhagic Stroke of Subacute Stage Using Pharyngeal Neuromuscular Electrical Stimulation and Mendelsohn Manuever
}

\author{
Author \\ Prof. V.Vijayaraj M.P.T., Ph.D (Research Scholar) \\ HoD, Department of Neurology, Nandha College of Physiotherapy Erode-52
}

\begin{abstract}
Background: Swallowing is a complicated mechanism, principally because the pharynx sub serves respiration as well as swallowing. Dysphagia is common after stroke, associated with increased death and dependency, and treatment options are limited. Pharyngeal Neuromuscular Electrical Stimulation with Mendelsohn manuever is a novel treatment for post stroke. This study focuses on specific treatment for Dysphagia as well as the improvement strategies between the ischemic and hemorrhagic stroke.

Method: The study sample comprised 30 patients, of which 15 were ischemic stroke patients and 15 were haemorrhagic stroke patients who are have a age between 40 to 60years. The median time interval between and FOIS \& DOSS applied before and after therapy was 2 weeks. Among 30 patients were treated with Neuromuscular Electrical stimulation with Mendelsohn Manuever was given for both the groups.

Result: The paired ' $t$ ' test values have shows that Pharyngeal Neuromuscular Electrical Stimulation with Mendelsohn manuever was more effective in both ishemic and haemorraghic stroke patients. The unpaired ' $t$ ' test values have shown that there was significant difference between two groups in showing improvement in their swallowing between hemorrhagic than ischemic type of subacute stroke patients .

Conclusion: There is significant difference between the improvement of dysphagia in between ischemic and hemorrhagic stroke of subacute stage using neuromuscular pharyngeal stimulation with Mendelsohn manuever. Further concluded that the Patients with hemorrhagic stroke was recovered faster than the ischemic stroke.

Keywords: Dysphagia, Pharyngeal Neuromuscular Electrical Stimulation, Mendelsohn manuever, Functional Oral Intake Scale, Dysphagia Severity and Outcome Scale.
\end{abstract}

\section{Introduction}

Cerebro Vascular Accident is defined as the sudden onset of neurological symptoms resulting from a disturbance of blood supply to the brain Clinically a variety of focal deficits are possible, including changes in the level of consciousness and impairments of sensory, motor, cognitive, perceptual and language functions to be classified as stroke, neurological deficits must persist for at least 24 hours. Motor deficits are characterized by paralysis or weakness, typically on the side of the body opposite the side of lesion. Swallowing is a complicated mechanism, principally because the pharynx sub serves respiration as well as swallowing. The pharynx is converted for only a few seconds at a time into a tract for propulsion of food. It is especially important that 
respiration not be compromised because of swallowing. A swallowing disorder or dysphagia is difficulty in swallowing, saliva, water or food. Dysphagia occurs in $45 \%-65 \%$ patients after a stroke. Mainly dysphagia occurs hemispheric stroke and brainstem stroke. According to Clarkson (2011), swallowing is a complete act involving 5 nerves and 25 muscles. Dysphagia is mainly due to $50 \%$ of acute stroke patients but is resolved in the majority within 2 weeks. Persistent dysphagia beyond this period is associated with increasing mortality higher dependence and hospitalization. Different therapeutic strategies have been introduced to treat swallowing impairment. The rehabilitation of swallowing treatment are compensatory technique including postural adjustment, supraglottis swallowing, and the effortful swallowing have been reported as the standard treatment for stroke survivors with dysphagia. In our study treatment for dysphagia is Neuro Muscular Pharyngeal Electrical Stimulation with Mendelsohn Manuever has been advocated as an adjunct to swallowing therapy.

\section{Aim of the Study}

The aim of this study is to compare the improvement of dysphagia in between ischemic and hemorrhagic stroke of subacute stage using neuromuscular pharyngeal stimulation with Mendelsohn manuever.

Materials and Methodology
Materials
$>$ Couch
$>$ Pillow
$>$ Bedsheets
$>$ Electrical stimulator
$>$ Bowl with water
$>$ Electrodes
$>$ Cable
$>$ Lint cloth
$>$ Salt
$>$ Mackintosh sheets

Methodology

Study Design

Sampling Method

$>$ Convenient Sampling

\section{Sample Sizes}

is Sample size is 30 subjects

$>$ Group A-15 patients

$>$ Group B-15 patients

\section{Source of Data}

$>$ RKR Neuro Speciality Hospital, Erode.

$>$ Government headquarters hospital, Erode.

$>$ Out Patient Department -Nandha College of Physiotherapy, Erode.

\section{Population}

$>$ Patients with age group of 40-60years having dysphagia in stroke of subacute stage

\section{Inclusion Criteria}

$>$ Patients with all type of stroke

$>$ Patients within 1 month of duration

$>$ Patients willing to participate in the study

$>$ Age group between 40 to 60 years

$>$ Both gender with swallowing difficulty

\section{Exclusion Criteria}

$>$ Age more than 60 and below 40 years

$>$ Patients with other type of dysphagia (e.g dysphagia in Cancer)

$>$ Patients with ventilator support

$>$ Patients with tracheostomy

$>$ Uncooperative Patients

$>$ Patients with cardio complication

$>$ Patients with other musculoskeletal disorder

$>$ Patients using hearing AIDS

$>$ Cognitive impairment (score less than 24 out of 30 in mini mental state examination)

$>$ Patients who had multiple stroke

\section{Study Duration}

10 Months

\section{Treatment Duration}

$>$ Study was carried out for 2 weeks for each individual.

$>$ Pharyngeal Neuromuscular Electrical Stimulation was performed once in a day.

$>$ Mendelsohn Manueverwas performed twice a day. 


\section{Parameter}

$>$ Functional Oral Intake Scale

$>$ Dyphagia Outcome and Severity Scale

\section{Procedure}

Subjects were selected by convenient sampling method. 30 subjects who fulfilled inclusion and exclusion criteria were selected by random sampling method, out of them 15 were allotted in Group A and 15 in Group B.

Subjects were clearly explained about the study and written informed consent was obtained from the subjects or from their caregivers.

After completing the informed consent and they were explained about the scale and the scale was administered.

Proper instructions such as purpose, safety measures, comfort, precautions and psychological support were given to the subjects.

$>$ All vital signs were checked.

$>$ While doing the assessment, the subject's willingness to continue the procedure with or without rest was given preference.

Both Group A and Group B subjects were involved for Pre test assessment.

Group A consist of 15 subjects in sub acute stage of ischemic stroke with dyphagia underwent Pharyngeal Neuromuscular Electrical Stimulation once in a day and Mendelsohn manuever twice a day.

- Group B consist of 15 subjects in sub acute stage of hemorrhagic stroke with dyphagia underwent Pharyngeal Neuromuscular Electrical Stimulation once in a day and Mendelsohn manuever twice a day

The total duration is 30 minutes.

\section{Pharyngeal Neuromuscular Electrical Stimulation}

The 15 subjects were involved for pre-test and post-test assessment by both Functional Oral
Independent Scale and Dysphagia Outcome Severity Scale. The pre-test values taken through the scale of Functional Oral Intake Scale the score is between 1 to 3 and then treatment sessions were 7 days per week for 30-90contractions for each muscle. The subjects could receive a maximum of 15 sessions. Placing the electrode on one or several external site on the anterior neck to which an electrical current is applied to peripheral tissues. Position (A) included two sets of electrode with an electrical current of 10. 0 MA located on each side of the midline, above and beneath the lesser horns of the hyoid bone, on the mylohyoid muscle and on the thyroid muscles. Position (B) one set of the electrodes with on electrical current upto 17.5 MA located on each side of mouth, on the orbicularis orismuscle and the masseter muscle.

\section{Mendelsohn Manuever}

The subjects are postioned in comfortable position either sitting half lying. This exercise is done to improve swallowing. It helps to raise the larynx and open the esophagus when swallowing. Most often, these exercises should not be done with food in your mouth. Swallow your saliva several times and pay attention to your neck as you swallow. Feel your voice box, also called your Adam's apple, lift and lower as you swallow. Now, swallow and feel your voice box lift but do not let it drop. Hold it with your muscles for 2 seconds. Release and then repeat 5times

\section{Data Presentation And Stastistical Analysis Statistical Tools}

The statistical tools used in the study are paired ttest and unpaired t-test.

\section{Paired ' $T$ '-Test}

The paired t-test was used to find out the statistical significance between pre and post t-test values of DHI and VAS before and after treatment for Group A and Group B. 
Formula for Paired T -Test,

$$
\begin{gathered}
S=\sqrt{\frac{\sum(x-\bar{x})^{2}}{n-1}} \\
\mathrm{t}=\frac{\bar{d} \sqrt{n}}{s}
\end{gathered}
$$

$\mathrm{d}=$ difference between the pre test $\mathrm{V}_{\mathrm{s}}$ post test

$\bar{d}=$ Mean difference

$\mathrm{n}=$ Total number of subjects

$\mathrm{S}=$ Standard deviation

\section{Unpaired ' $T$ '- Test}

The unpaired t-test was used to compare the statistically significance difference of DHI and VAS before and after treatment for Group A and Group B.

\section{Formula for Unpaired $\mathbf{T}-$ Test $S=$}

$$
\begin{gathered}
\sqrt{\frac{\left(n_{1}-1\right) s_{1}{ }^{2}+\left(n_{2}-1\right) s_{2}{ }^{2}}{n_{1}+n_{2}-2}} \\
\mathrm{t}=\frac{\left|\bar{x}_{1}-\bar{x}_{2}\right|}{s \sqrt{\frac{1}{n_{1}}+\frac{1}{n 2}}}
\end{gathered}
$$

$\mathrm{n}_{1}=$ Total number of subject in group $\mathrm{A}$

$\mathrm{n}_{2}=$ Total number of subject in group $B$

$\mathrm{x}_{1}=$ Difference between pre test and post test of

Group A

$\overline{x_{1}}=$ Mean difference between pre test and post test of group A

$\mathrm{X}_{2}=$ Difference between pre test and post test of Group B

$\overline{\mathrm{X}}_{2}=$ Mean difference between pre test and post test of Group B

$\mathrm{S}=$ Standard Deviation

Mean Difference between Group A and Group B of FOIS

\begin{tabular}{|l|c|c|}
\hline Groups & \multicolumn{2}{|c|}{ Mean Difference } \\
\cline { 2 - 3 } & $\begin{array}{c}\text { Pre } \\
\text { Treatment }\end{array}$ & $\begin{array}{c}\text { Post } \\
\text { Treatment }\end{array}$ \\
\hline Group A & 1.8 & 5.2 \\
\hline Group B & 1.3 & 6.3 \\
& & \\
\hline
\end{tabular}

Mean Difference between Group A and Group B of Doss

\begin{tabular}{|l|c|c|}
\hline Groups & \multicolumn{2}{|c|}{ Mean Difference } \\
\cline { 2 - 3 } & $\begin{array}{c}\text { Pre } \\
\text { Treatment }\end{array}$ & $\begin{array}{c}\text { Post } \\
\text { Treatment }\end{array}$ \\
\hline Group A & $` 1.8$ & 5.8 \\
\hline Group B & 1.3 & 6.3 \\
\hline
\end{tabular}

Standard Deviation between Group A and Group B of FOIS

\begin{tabular}{|l|c|c|}
\hline Groups & \multicolumn{2}{|c|}{ Standard Deviation } \\
\cline { 2 - 3 } & $\begin{array}{c}\text { Pre } \\
\text { Treatment }\end{array}$ & $\begin{array}{c}\text { Post } \\
\text { Treatment }\end{array}$ \\
\hline Group A & 0.801 & 0.818 \\
\hline Group B & 0.53 & 0.854 \\
& & \\
\hline
\end{tabular}

Standard Deviation between Group A and Group B of DOSS

\begin{tabular}{|l|c|c|}
\hline Groups & \multicolumn{2}{|c|}{ Standard Deviation } \\
\cline { 2 - 3 } & $\begin{array}{c}\text { Pre } \\
\text { Treatment }\end{array}$ & $\begin{array}{c}\text { Post } \\
\text { Treatment }\end{array}$ \\
\hline Group A & 0.51 & 0.59 \\
\hline Group B & 0.54 & 0.70 \\
& & \\
\hline
\end{tabular}


Comparison of Paired ' $T$ ' test and Table Value between Pre and Post Treatment Values of Group A and Group B FOIS

\begin{tabular}{|c|c|c|c|c|}
\hline \multirow[t]{2}{*}{ Groups } & \multicolumn{2}{|c|}{ Calculated ' $T$ ' Value } & & \multirow{2}{*}{$\begin{array}{c}\text { Significanc } \\
\text { e }\end{array}$} \\
\hline & $\begin{array}{c}\text { Pre } \\
\text { Treatment }\end{array}$ & $\begin{array}{c}\text { Post } \\
\text { Treatment }\end{array}$ & $\begin{array}{l}\text { Table } \\
\text { Value }\end{array}$ & \\
\hline Group A & 0.75 & 3.08 & 2.15 & Significant \\
\hline Group B & 1.22 & 2.33 & 2.15 & Significant \\
\hline
\end{tabular}

Comparison of Paired ' $T$ ' Test and Table Value between Pre and Post Treatment Values of Group A and Group B Doss

\begin{tabular}{|c|c|c|c|c|}
\hline \multirow[t]{2}{*}{ Groups } & \multicolumn{2}{|c|}{ Calculated ' $T$ ' Value } & & \multirow{2}{*}{$\begin{array}{c}\text { Significa } \\
\text { nce }\end{array}$} \\
\hline & $\begin{array}{c}\text { Pretreat } \\
\text { ment }\end{array}$ & $\begin{array}{c}\text { Post } \\
\text { Treatment }\end{array}$ & $\begin{array}{l}\text { Table } \\
\text { Value }\end{array}$ & \\
\hline Group A & 1 & 2.72 & 2.15 & $\begin{array}{c}\text { Significan } \\
t\end{array}$ \\
\hline Group B & 1.37 & 2.73 & 2.15 & $\begin{array}{c}\text { Significan } \\
t\end{array}$ \\
\hline
\end{tabular}

Values of Unpaired ' $T$ ' Test for FOIS and Doss

\begin{tabular}{|l|l|l|l|}
\hline Parameters & $\begin{array}{l}\text { Unpaired 'T' } \\
\text { Test }\end{array}$ & $\begin{array}{l}\text { Table } \\
\text { Value }\end{array}$ & Significance \\
\hline Fois & 12.14 & 2.05 & Significant \\
\hline Doss & 24.5 & 2.05 & Significant \\
\hline
\end{tabular}

\section{Results}

The study sample comprised 30 patients, of which 15 were ischemic and 15 were haemorrhagic stroke patients, who are have a age between 40 to 60 years. The median time interval between and FOIS \& DOSS questionnaires applied before and after therapy was 2 weeks. Thirty patients were treated with Neuromuscular Electrical stimulation with Mendelsohn Manuever for both the groups. The Mean difference, Standard Deviation, Paired ' $t$ ' Test and Unpaired ' $t$ ' test values are assessed by both FOIS and DOSS are calculated and tabulated. The results shows that the paired ' $t$ ' test values between two groups has shows that Pharyngeal Neuromuscular Electrical Stimulation with Mendelsohn manuever was more effective in both ishemic and haemorraghic stroke patients. The unpaired ' $t$ ' test values have shown that there was significant difference between two groups in showing improvement in their swallowing between haemorrhagic than ischemic type of sub acute stroke patients .

\section{Discussion}

While consideration of Dysphagic sub acute stroke patients, I found there was a effective and good improvement in both oral muscle strength and swallowing function.

There was a statistically significant difference in the impact of swallowing in patients sub acute stoke in both the Groups. This indicates that there is a positive effect of this maneuver and Pharyngeal Neuromuscular Electrical Stimulation in having difficulty among swallowing in patients with dysphagia. This study performed Mendelsohn manuever for the improvement of oral functions, electrical stimulation was applied on swallowing related uscle in the anterior neck region and the facial muscles. Moreover, facial muscles contribute to mastricatory activities while the lip muscles contribute to maintain in oral closer during swallowing to generate appropriate intra oral pressure. Improving the strength of this oral muscle can increase the intra oral pressure during swallowing and have a positive effect in the pharyngeal phase as well. A previous study reported that electrical stimulation in patients with dysphagia can activate the swallowing muscles. It is an effective method for inducing antero superior movement of the hyoid, which has a direct impact on the airway protection mechanism, and can help to decrease aspiration. This supports the result of present study. Hence, I performed Neuro Muscular Electrical Stimulation with Mendelsohn manueverin sub acute stroke of both ischemic and haemorrhagic patients. This study shows that there is remarkable improvement in both the oral muscle strength and swallowing function for haemorrhagic patients. This study has proved that Neuro Muscular Electrical Stimulation with Mendelsohn manueveris more effective in 
hemorrhagic stroke patients than the ischemic stroke patients.

\section{Limitations}

$>$ The study has been conducted on small sized sample only.

$>$ This study took shorter duration to complete.

$>$ The study limitations include the patients of TIA and RIND are not included.

$>$ This study is not extended more than 2 weeks for a patient due to time constraint.

\section{Recommendations}

$>$ A similar study may be extended with larger sample.

$>$ This study may be extended to chronic dysphagic patients

$>$ This study can be further included the patients who can get a dysphagia other than stroke.

$>$ The future study can be compared with various manuevers and types of therapeutic currents also.

\section{Summary and Conclusion}

Patients with stroke present with a history of swallowing difficulty. Whereas a variety of therapeutic approach have been described, Mendelsohn manueveris a simple effective treatment for most patients with Dysphagia. In our samples, Pharyngeal Neuromuscular Electrical Stimulation with Mendelsohn manuever resulted in a positive impact on the swallowing ability of the patients with sub acute stroke. The FOIS score and DOSS Scale differences in subscute stroke patients with dysphagia patients before and after treatment were statistically significant. Through the results, alternate hypothesis is accepted and also the study could be concluded that There is significant difference between the improvement of dysphagia in between ischemic and hemorrhagic stroke of sub acute stage using Neuro Muscular Pharyngeal Stimulation with Mendelsohn Manuever. Further concluded that the Patients with hemorrhagic stroke was recovered faster than the ischemic stroke.

\section{Bibliography}

1. Bath PM, Bath FJ, Smithard DG Interventions for dysphagia in acute stroke. 2000;(2):CD000323.

2. Bath PM, Lindenstrom E, Boysen G, De Deyn P, Friis P, Leys D, Marttila R, Olsson J, O'Neill D, Orgogozo J, Ringelstein B, van der Sande J, Turpie AG. Tinzaparin in acute ischaemic stroke (TAIST): a randomised aspirin-controlled trial. 2001 Sep 1;358(9283):702-10

3. Cecconi E, Di Piero V. Dysphagia-pathophysiology, diagnosis and treatment. 2012;30:86-9. doi: 10.1159/000333423. Epub 2012 Feb 14.

4. Chun MH, Kim D, Chang MC Comparison of dysphagia outcomes between rostral and caudal lateral medullary infarct patients.2017 Jan 31:1-6. doi: $\quad 10.1080 / 00207454.2017 .1282479$. [Epub ahead of print]

5. Cohen SM, Dupont WD, Courey MS. Quality-of-life impact of non-neoplastic voice disorders: a meta-analysis. 2006 Feb;115(2):128-34.

6. Cohen SM, Elackattu A, Noordzij JP, Walsh MJ, Langmore SE. Palliative treatment of dysphonia and dysarthria. 2009 Feb;42(1):107-21, x. doi: 10.1016/j.otc.2008.09.010.

7. Dziewas R, Warnecke $\mathrm{T}$, Olenberg S, Teismann I, Zimmermann J, Kramer C, Ritter M, Ringelstein EB, Schabitz WR. Towards a basic endoscopic assessment of swallowing in acute stroke development and evaluation of a simple dysphagia score. 2008;26(1):41-7. doi: 10.1159/000135652. Epub 2008 May 30.

8. Ertzgaard P, Ward AB, Wissel J, Borg J. Practical considerations for goal attainment scaling during rehabilitation following 
acquired brain injury $2011 \mathrm{Jan} ; 43(1): 8-14$. doi:10.2340/16501977-0664.

9. Foley N, Teasell R, Salter K, Kruger E, Martino R. Dysphagia treatment post stroke: a systematic review of randomised controlled trials.2008 May;37(3):258-64. doi: 10.1093/ageing/afn064.

10. Foley NC, Martin RE, Salter KL, Teasell RW A review of the relationship between dysphagia and malnutrition following stroke.2009 Sep;41(9):707-13. doi: 10.2340/16501977-0415.

11. Freed ML, Freed L, Chatburn RL, Christian M. Electrical stimulation for swallowing disorders caused by stroke.2001 May;46(5):466-74.

12. Geeganage C, Beavan J, Ellender S, Bath PM Interventions for dysphagia and nutritional support in acute and subacute stroke. 2012 Oct 17;10:CD000323. doi: 10.1002/14651858.CD000323.pub2.

13. Hamdy S, Aziz Q, Rothwell JC, Crone R, Hughes D, Tallis RC, Thompson DG Explaining oropharyngeal dysphagia after unilateral hemispheric stroke. 1997 Sep 6;350(9079):686-92.

14. Jayasekeran V, Singh S, Tyrrell P, Michou E, Jefferson S, Mistry S, Gamble E, Rothwell J, Thompson D, Hamdy S Adjunctive functional pharyngeal electrical stimulation reverses swallowing disability after brainlesions. 2010 May;138(5):173746. doi: 10.1053/j.gastro.2010.01.052. Epub 2010 Feb 2.

15. Langmore SE, Grillone G, Elackattu A, Walsh M. Disorders of swallowing: palliative care. $2009 \mathrm{Feb}$;42(1):87-105, ix. doi: 10.1016/j.otc.2008.09.005.

16. Lim KB, Lee HJ, Lim SS, Choi YI. Neuromuscular electrical and thermaltactile stimulation for dysphagia caused by stroke: a randomized controlled trial. 2009 Feb;41(3):174-8. doi: 10.2340/165019770317 .
17. Ragab S, Soda H, Warusevitane A, Woisard V, Hamdy S; Pharyngeal Electrical Stimulation for Treatment of Dysphagia in Subacute Stroke: A Randomized Controlled Trial.

18. Restivo DA, Casabona A, Centonze D, Marchese-Ragona R, Maimone D, Pavone A Pharyngeal electrical stimulation for dysphagia associated with multiple sclerosis:a pilot study.2013 May;6(3):41823. doi: 10.1016/j.brs.2012.09.001. Epub 2012 Sep 23.

19. Scutt P, Lee HS, Hamdy S, Bath PM Pharyngeal Electrical Stimulation for Treatment of Poststroke Dysphagia: Individual Patient Data Meta-Analysis of Randomised Controlled Trials. 2015;2015: 429053. doi: 10.1155/2015/429053. Epub 2015 Nov 24.

20. Tan C, Liu Y, Li W, Liu J, Chen L Transcutaneous neuromuscular electrical stimulation can improve swallowing function in patients with dysphagA1:A25ia caused by non-stroke diseases: a metaanalysis.2013 Jun;40(6):472-80. doi: 10.1111/joor.12057. Epub 2013 Apr 23. 